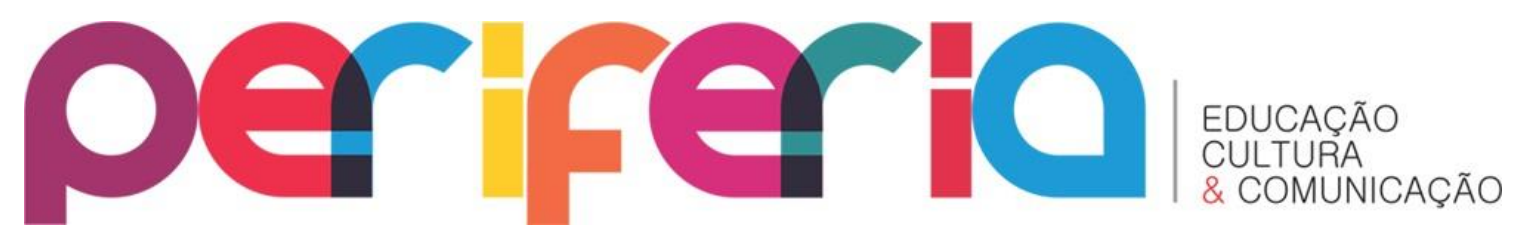

\title{
A INFLUÊNCIA DO PATRIARCADO JUNTO AS MULHERES DE COMUNIDADES TRADICIONAIS NA BAIXADA CUIABANA-MT
}

\author{
Lisanil da Conceição Patrocínio Pereira ${ }^{1}$ \\ Universidade do Estado de Mato Grosso \\ Waldinéia Antunes de Alcântara Ferreira ${ }^{2}$ \\ Universidade do Estado de Mato Grosso
}

\section{Resumo}

O Nedet (Núcleo de Desenvolvimento Territorial da Baixada Cuiabana) da Unemat (Universidade do Estado de Mato Grosso) tem desenvolvido trabalho junto às mulheres do Território, contribuindo com a autonomia de mulheres que vivem em áreas rurais para que tenham renda e mais independência no ambiente familiar. Nesse sentido, temos feito Encontros de Mulheres dos Territórios Rurais e da Cidadania do Estado de Mato Grosso. Já foram organizados três eventos, um como evento paralelo ao SEMIEDU (Seminário de Educação da UFMT), em conjunto com grupos de pesquisa da UFMT e os outros dois nos espaços de Comunidades Tradicionais Camponesas. O objetivo dos respectivos eventos foram expor para a comunidade acadêmica e à população, produções científico-culturais produzidas no âmbito dos Comitês de Mulheres dos Colegiados Rurais. Carece destaque que a criação e articulação do Comitê de Mulheres leva em conta o empoderamento das mulheres para que atuem no meio em que vivem da forma mais independente possível, sobretudo que se levantem contra a violência de gênero muito presente, sobretudo no campo, onde os meios de proteção são mais difíceis de chegar. Também é uma forma de contribuir com o conhecimento acerca do patriarcado, para que possam reivindicar um lugar de igualdade junto ao lar; assumir o espaço de decisão no lote rural; decidir no que investir com o dinheiro da produção e sobre os espaços de morada da comunidade rural, locais de convívio e bem viver.

Palavras-chave: mulheres; comunidades tradicionais; território

\footnotetext{
1 Pós-Doutorado em Ciências Humanas pela Universidade Federal de Mato Grosso, UFMT (2015-2016), Doutora, mestre, bacharel e licenciada em Geografia. Licenciada em Pedagogia e Bacharel em Administração. Professora adjunta da UNEMAT - Universidade do Estado de Mato Grosso na área de Metodologia Científica. Atua no Nedet (Núcleo de Desenvolvimento Territorial da Baixada Cuiabana). lisanilpereira@hotmail.com

2 Doutorado em Educação pela Universidade Federal do Rio Grande do Sul. Faculdade de Educação. waldineiaferreira@hotmail.com
}

Periferia, v. 10, n. 2, p. 103-118, jul./dez. 2018

DOI: $10.12957 /$ periferia.2018.33321 


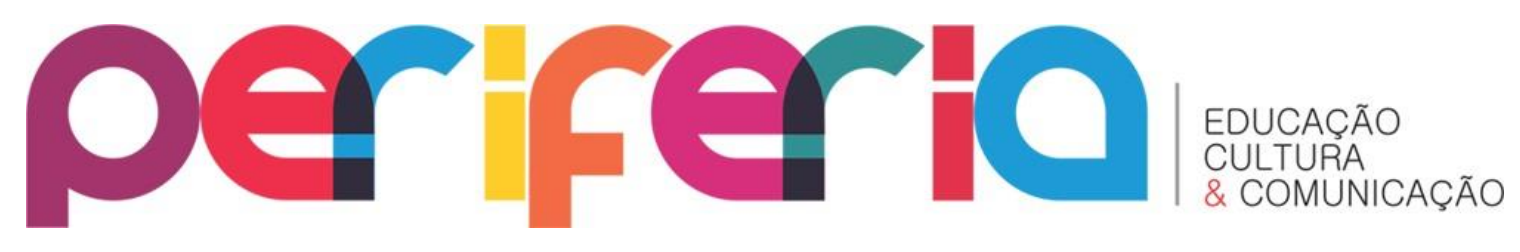

\title{
THE INFLUENCE OF THE PATRIARCHY TOGETHER WOMEN OF TRADITIONAL COMMUNITIES IN BAIXADA CUIABANA-MT
}

\begin{abstract}
The NEDET (Center of Territorial Development of Baixada Cuiabana) of Unemat (University of the State of Mato Grosso) has worked with the women of the Territory. It has been contributing with the autonomy of women who live in rural areas so that they have income and more independence in the environment family. In this sense, we have held Women's Meetings of the Rural Territories and Citizenship of the State of Mato Grosso. Three events have already been organized, one as a parallel event to SEMIEDU (Education Seminar), together with Federal University of Mato Grosso - UFMG research groups and the other two in the spaces of Traditional Peasant Communities. The objective of the respective events was to expose to the academic community and to the population, scientific-cultural productions produced within the framework of the Committees of Women of the Rural Associations. It is important to note that the creation and coordination of the Women's Committee takes into account the empowerment of women to act in the environment in which they live as independently as possible, especially if they stand up against gender-based violence, especially in the countryside, where means of protection are more difficult to reach. It is also a way of contributing with the knowledge about patriarchy, so that they can claim a place of equality next to the home; assume their decision space in the rural lot; decide on what to invest with the production money and on the living spaces of the rural community, places of well live.
\end{abstract}

Keywords: women; traditional communities; territory 


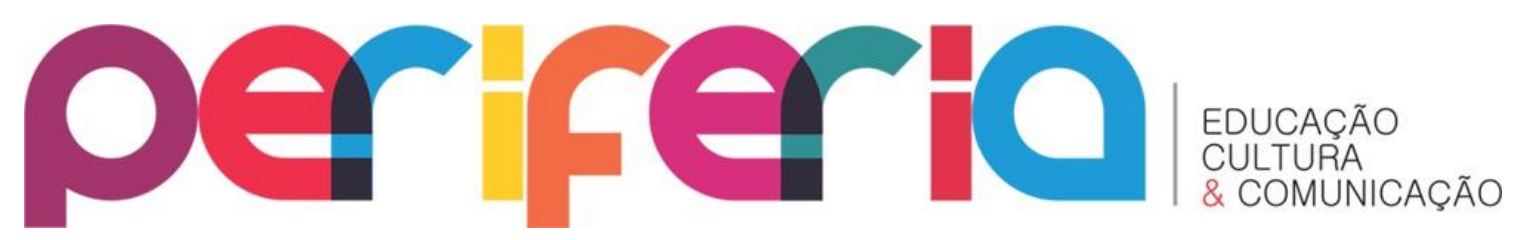

INTRODUÇÃO

O presente artigo relata alguns resultados da articulação do Comitê de Mulheres do Colegiado do Território da Cidadania da Baixada Cuiabana no Estado de Mato Grosso, o estímulo à criação dos Comitês de Mulheres no âmbito dos colegiados territoriais foi uma das Políticas Públicas do extinto MDA (Ministério do Desenvolvimento Agrário), concomitante ao incentivo a criação do Comitê de Juventude e Povos Tradicionais e Quilombolas no âmbito do Território. Este trabalho foi possivel através da articulação entre o NEDET (Núcleo de Desenvolvimento Territorial da Baixada Cuiabana), Eco Cut (Escola de Formação da Central Única dos Trabalhadores) e CFES (Centro de Formação da Economia Solidária). O objetivo principal do Nedet foi o de articular e assessorar o Colegiado do Território da Cidadania da Baixada Cuiabana. A articulação entre o Nedet/Unemat e Eco Cut foi projeto importante de fortalecimento das mulheres e sua inserção e ou formação em Economia Solidária.

A formação inicial do Comitê de Mulheres começa a partir de uma reunião do Colegiado e uma Audiência Pública da Agricultura Familiar que ocorreu na Central de Comercialização da Agricultura Familiar do Território, em CuiabáMT, no dia 21 de junho de 2015. O Comitê passa por reestruturação com elaboração de Ata Extraordinária em fevereiro de 2016 no Município de Chapada dos Guimarães. A partir dessa formação inicial foi possível organizar o desenvolvimento de uma metodologia de trabalho entre as instituições parceiras (Nedet e Eco Cut) com a formulação de um planejamento que contou com a participação da Delegacia Federal do MDA em MT foi realizado assim, o Percurso de Formação com os Comitês de Mulheres e da Juventude.

Anunciamos a partir de agora os temas abordados pela equipe de trabalho: Economia Solidária e Inclusão Produtiva; Educação e Inclusão Produtiva; Fala Feminista sobre Inclusão Produtiva, Organização e Autonomia; Políticas Inclusão Produtiva - PAA (Plano de Aquisição de Alimentos) e PNAE (Plano Nacional de Alimentação Escolar); Relato de Experiência a partir da 


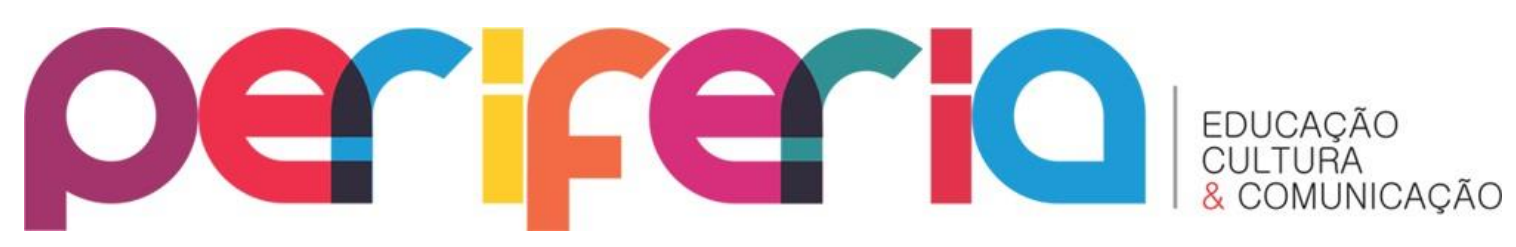

formação e como montar um Micro Empreendimento: Organização e Gestão Financeira.

Assim, a organização deste artigo tem a mesma significância das vivências, e nesse sentido relatamos aqui o acompanhamento e a compreensão vivida, ao mesmo tempo transpor a análise estruturalista do cientificismo que o pensa em pedaços, em caixinhas entendendo que dessa forma é possível compreender tudo ao redor. Essa compreensão reducionista tem sido questionada, pois os movimentos da mente não são apenas separar para compreender, e depois juntar tudo de novo, mas sim, ir além, ou seja, fazer os dois movimentos, analisar as partes e ver o todo, ver as referências ao redor que geram identidades, identificar interlocuções em teias que significam as vivências produzidas. É nessa teia do NEDET que procuramos compreender o papel das Mulheres, nas ações do Colegiado do Território da Cidadania da Baixada Cuiabana, por unir os dois movimentos da mente que são reais como manifestação dos fenômenos vivos do mundo para nós. Procuramos desta forma, então, compreender a dialogicidade presente no Colegiado do Território utilizando os dois movimentos, que definimos, de análise pormenorizada e compreensão holística, e o tentamos fazê-lo a partir de uma compreensão fenomenológica.

\section{MULHERES DO TERRITÓRIO DA CIDADANIA DA BAIXADA CUIABANA}

As mulheres da Baixada Cuiabana, são: agricultoras, catadoras, farinheiras, pescadoras, professoras, domésticas, donas de casa, artesãs, costureiras, doceiras, rezadeiras, contadoras de histórias. E estas mulheres contribuem na economia doméstica da família e são exemplos de resistência dentro de suas comunidades ao assumirem responsabilidades como a educação, geração de renda em cooperativas, associações e/ou no próprio lote particular, o respeito e preocupação com a sustentabilidade, espaços de liderança em sindicatos, associações, grupos religiosos. 


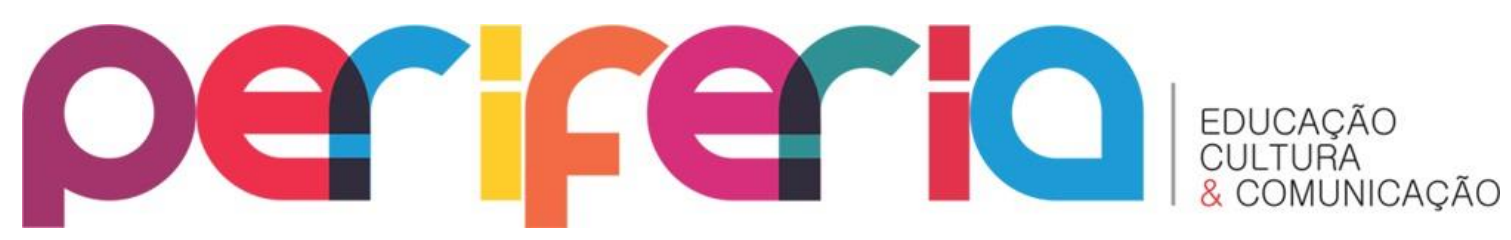

As mulheres do Território da Cidadania da Baixada Cuiabana nos mostram que tentam romper com as imposições da sociedade patriarcal que ainda hoje que sejamos apenas reprodutoras de filhos.

Além do trabalho de geração de renda, as mulheres do campo tem carga horária com dupla e tripla jornada de trabalho, em que a hierarquia dos papéis desempenhados por homens e por mulheres coloca-as numa condição de exploração do trabalho, o que acaba sendo naturalizado por elas. Dentre as suas atividades estão a tarefa de cuidar dos filhos, além de limpar e manter a casa organizada, preparar o cardápio e fazer a comida de acordo com os ingredientes que tem na casa, lavar as vasilhas e as roupas de todos os integrantes da família, tarefa essa que raramente tem a ajuda de sexo masculino, além de estender a roupa no varal, recolher, passar e guardar as roupas. Algumas mulheres entregam as roupas para o marido dentro do banheiro o marido nem mesmo escolhe que tipo de roupa vestir, tudo é feito pela mulher que o trata como filho e lamentavelmente os filhos homens já crescem com esse hábito reproduzindo o costume patriarcal na nova família que se organiza. Além de tudo isso, sempre que adoece alguém da familia como o pai ou a mãe, recae sobre a mulher a responsabilidade de cuidar do idoso, sempre é a mulher que ajuda nas tarefas da escola dos filhos.

A manutenção da mulher no ambiente doméstico é fator determinante também para o manutenção do sistema capitalista, patriarcal e colonial como ensina Santos (2006; 2016a). Esta é uma relação enraizada estruturalmente nesta sociedade capitalista-patriarcalista-colonial, e sua superação encontrase em processos lentos, pois há a necessidade de descolonizarmos nossas mentes e corpos a respeito das relações desiguais de gênero para que um dia as mulheres possam escolher se querem fazer o doce ou escrever poemas, conforme era o desejo da grande poetisa da Cidade de Goiás, Cora Coralina.

\section{O saber e o fazer da mulher no Quilombo de São Benedito - Poconé-MT:}

Para falar das mulheres do Quilombo São Benedito é preciso falar, primeiramente, da sua história. Assim, o Quilombo de São Benedito está no Periferia, v. 10, n. 2, p. 103-118, jul./dez. 2018 


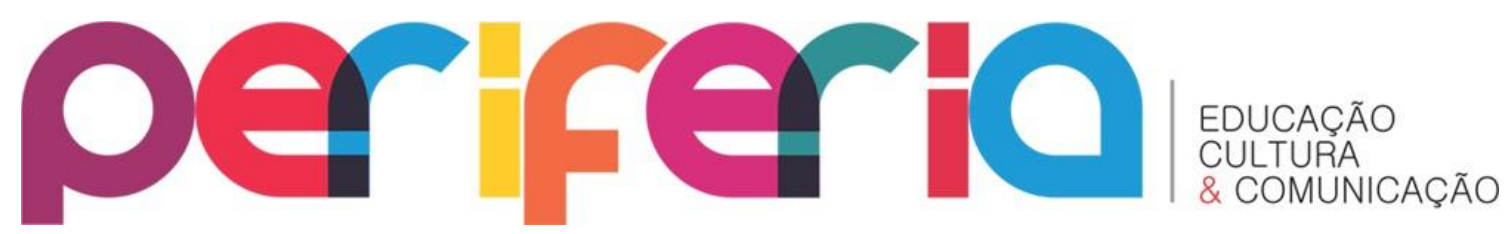

interior do Município de Poconé. Lugar de refúgio de escravos afrodescendentes, lugar de formação da cultura afro-brasileira, lugar de resistência, território certificado pela Fundação Palmares (instituição que reconhece as comunidades Quilombolas no país). São espaços humanos, que na atualidade designam-se como remanescente de quilombo, estes são fortalecidos pelos elementos de identidade e sentimento de pertença. São espaços decoloniais que pela vivência contrariam a ordem estabelecida.

Segundo relato das moradoras, essa comunidade é relativamente nova, e sua formação está ligada a ancestralidade dos povos ali residentes. Lugar feito no saber e no fazer da roça de mandioca de mulheres e homens que se organizam em processos de subsistência e de organização social. Uma mistura mística de fazer a farinha de mandioca na coletividade sob rezas e devoção a São Benedito. Igreja Cristã, e, santo negro revivificado na cor negra dos povos dos quilombos.

Mulheres que plantam, colhem, cascam, ralam, torram a farinha e entre esses trabalhos cantam para São Benedito... "Meu São Benedito, cheira cravo e rosa flor de laranjeira". Rememoram que os pais de São Benedito não queriam mais ter filhos para não gerar mais escravos, pois, os mesmos eram escravos. Seus pais vieram da Etiópia para a Sicília, mas, ainda tiveram Benedito. Benedito sempre foi muito insultado e suportou, tornou-se monge Franciscano. Quando morreu exalou cheiro de rosa e flor de laranjeira. Protetor do povo sofrido.

São elas as rezadeiras e as protagonistas do siriri (dança tradicional MatoGrossense) na comunidade. O trabalho é coletivo e as mulheres com sutileza assumem uma espécie de matriarcado, aliás, organização muito forte nas comunidades ribeirinhas do Estado de Mato Groso. Dizemos, isso porque as mães-mulheres assumem praticamente toda a tarefa educativa dos filhos/as e reúnem a família por gerações do seu lado. Desta forma, as atividades da roça de mandioca vai sendo realizada ao longo de vários anos e as mulheres estão nesta lida com tamanha importância, ainda que não se apercebam. Observamos que elas ditam a organização, os homens fazem as relações comerciais, mas, toda a costura do fazer-se cotidianamente tem um planejamento feminino. 


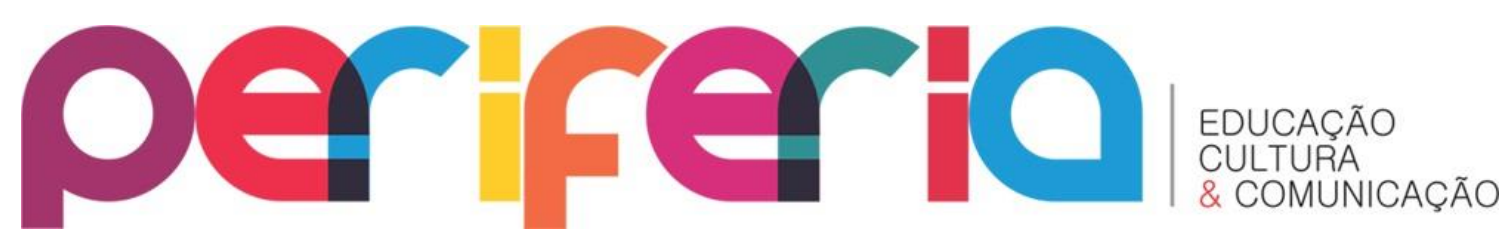

O comitê das mulheres de alguma forma evidenciou o protagonismo da mulher na roça, e, nas diversas ações dentro da comunidade. São elas que produzem o alimento sob o fogão de lenha e sob o forno de barro. Os homens são coadjuvantes trazem a lenha, fazem o fogo, mas, o sabor, o gosto, o fazer é produzido pelas mãos femininas e fortes das mulheres.

São as mulheres com o companheirismo dos homens que comercializam a farinha de São Benedito, resultado do trabalho e da relação empreendida com a terra. A farinha de São Benedito, produto advindo da agricultura familiar, ganha o mundo sendo comercializada em vários pontos comerciais, sobretudo nas feiras que funciona na Central Comercialização da Agricultura Familiar localizada em Várzea Grande. Atividade planejada pela política territorial do extinto MDA (Ministério de Desenvolvimento Agrário).

Para chegar a feira, é preciso levantar as 4:00 horas da manhã, sentir o orvalho no corpo, encontrar-se com a roça e colher a mandioca. Depois, as mulheres acendem o fogo, e o fogão de lenha queima e aquece... o corpo precisa se alimentar e alimento, histórias e trabalho se confundem... 0 resultado é a farinha, que é vendida e que realimenta as pessoas da comunidade.

O saber e o fazer da mulher do/no Quilombo de São Benedito é uma complexidade ancestral, construída sob histórias e memórias coletivas da necessidade de subsistência e de decolonialidade. 0 saber é aquele que se quer autônomo, que se quer reconhecido em seus direitos de ser/estar na comunidade e o de ser mulher. 0 fazer é o da coletividade, da cantoria, da vida em comunidade e do se fazer mulher de aprendizagens de um mundo que subestima a capacidade efêmera de ser feminina.

As reflexões aqui construídas são leituras de mulheres que se encontraram na cotidianidade da vida e do fazer-se mulher, no Quilombo ou fora dele. Os encontros de formação mencionados acima na introdução deste trabalho foram nossas formações, porque possibilitaram releituras e posicionamentos, acima de tudo empoderamento. Descobertas ocorreram: “[...] sempre trabalhamos sem a utilização de agrotóxicos, em coletividade... 


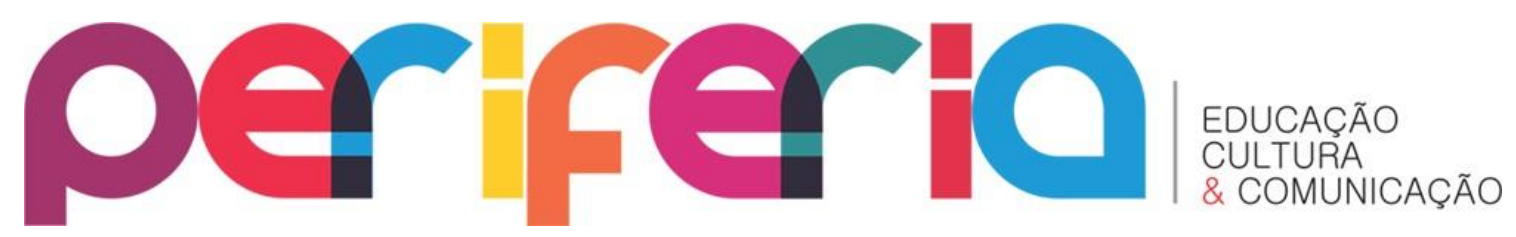

Acho que sempre trabalhamos dentro da economia solidária e com a agricultura familiar" (Fátima/Quilombo São Benedito).

Consideramos que o trabalho com o Comitê de Mulheres não foi uma tarefa fácil, mas foi desafiadora, pois as mulheres ainda sofrem de forma significativa com o que Boaventura de Souza Santos (2016b) apregoa como impeditivo de uma vida melhor que é o Capitalismo, Patriarcado e Colonialismo. As características patriarcais da sociedade determinam o que a mulher tem que ser e ou o espaço que ela deve ocupar, como o de ficar dona de casa, quieta, sem participar dos espaços de decisão.

Um bom exemplo é que dos 14 municípios apenas um possuía um sindicato rural com uma mulher presidenta, na gestão de 2013-2016. Nenhuma prefeitura tinha uma Secretaria Municipal de Agricultura tendo à frente uma mulher. Dentre as associações e cooraperativas são poucas as que têm uma mulher como presidenta, a exemplo da Coorlivre (Cooperativa de Agricultores de Nossa Senhora do Livramento) presidida por uma mulher.

Também na cidade Chapada dos Guimarães foi organizado o Curso Inicial de Economia Solidária do Estado de Mato Grosso tendo como objetivo propiciar aos participantes o entendimento do que é Economia Solidária e de como o Movimento de Economia Solidária e a Política estão organizados no Brasil e, em especial, em Mato Grosso tendo como pano de fundo a Política Territorial.

O Percurso Formativo do Curso Inicial de Economia Solidária resumiu-se na definição de Economia Solidária; qual a diferença entre um trabalho qualquer na comunidade e aquele considerado Economia Solidária; os Empreendimentos Solidários; as trocas de experiências; a produção de cultura; os desafios que surgem no trajeto; a inclusão social que acontece; o sentimento de ser cidadão novamente; o consumo consciente; a escolha que vai além do produto; escolha de confiança; Economia e Ecologia que se encontram; a parceria; o respeito ao ambiente natural; a troca que gera transformação e geração de renda na solidariedade.

A Formação integrou também as atividades do Seminário para consolidação do Comitê de Mulheres do Território da Cidadania da Baixada Cuiabana e ainda a reunião do Núcleo Diretivo do Colegiado. 


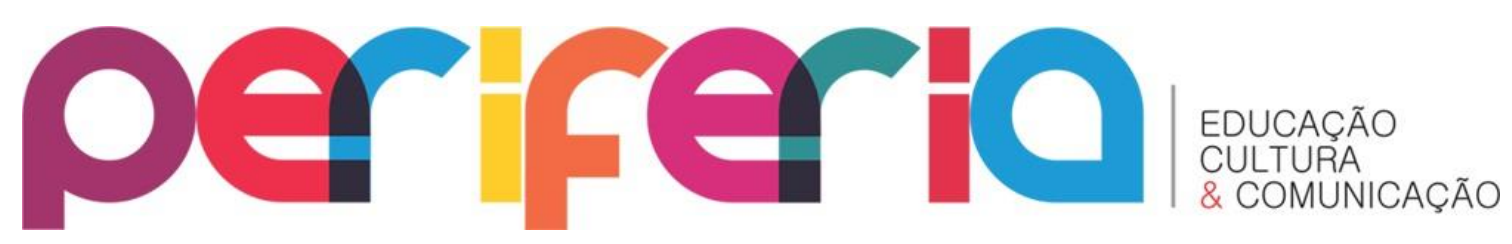

Foram trabalhados os Temas: "Economia Solidária": Produção, Comercialização e Consumo. Abordamos ainda sobre Produção, Planejamento, Organização do Empreendimento, Condições de Produção, o trabalho Coletivo, Estratégia Organizativas dos Empreendimentos de Economia Solidária, Comercialização, Comissão de Infraestrutura e outros.

Em paralelo ao trabalho de formação também tivemos o trabalho de mobilização junto às comunidades, para tanto estivemos em vários municípios, sobretudo na Comunidade de Agrovila das Palmeiras, Município de Santo Antônio de Leverger, com os Alunos do Curso de Agroecologia, bolsistas de Iniciação Jr do CNPq, a equipe gestora da escola, os pais e membros da COOPAMSAL, sempre com o cuidado de discutir com a comunidade o desenvolvimento do projeto e atuação de cada um na execução das ações.

Carece destaque o trabalho sobre associativismo e cooperativismo, junto a COOPAMSAL. Os alunos de Agroecologia vinculados ao CNPq têm produzindo polpas de frutas da região, farinha de castanha de babaçu, farinha de banana e doces em geral, para vender em uma feira na comunidade. Para potencializar esse trabalho de venda e exposição de produtos e que foi criado a Feira Itinerante da Agricultura Familiar do Território da Cidadania da Baixada Cuiabana, Feira esta que começou dentro das Jornadas dos Povos do Brasil e do I Encontro Estadual das Mulheres dos Territórios Rurais e da Cidadania do Estado de Mato Grosso.

Uma das últimas políticas deixadas pelo governo da Presidenta da República Dilma Roussef interrompida pelo golpe midiático, jurídico e parlamentar foi o lançamento do Edital do PROINF Mulheres (Programa de Infra Estrutura aos Territórios)/MDA voltado para os Colegiados que tem Comitê de Mulheres. Diante do Edital, mobilizamos as mulheres do território para tomar a decisão sobre qual o município era possível fazer o investimento. Assim foi feito e decidido encaminhar um projeto para a produção do Babacú para o Quilombo Mutuca em Nossa Senhora do Livramento, que tem a participação de mulheres e que conta com uma mulher na presidência da Associação. Após a decisão, encaminhamos a elaboração do projeto, visitamos o prefeito de Nossa Senhora do Livramento no dia 29/03/2016, para discutir procedimentos burocráticos Periferia, v. 10, n. 2, p. 103-118, jul./dez. 2018 


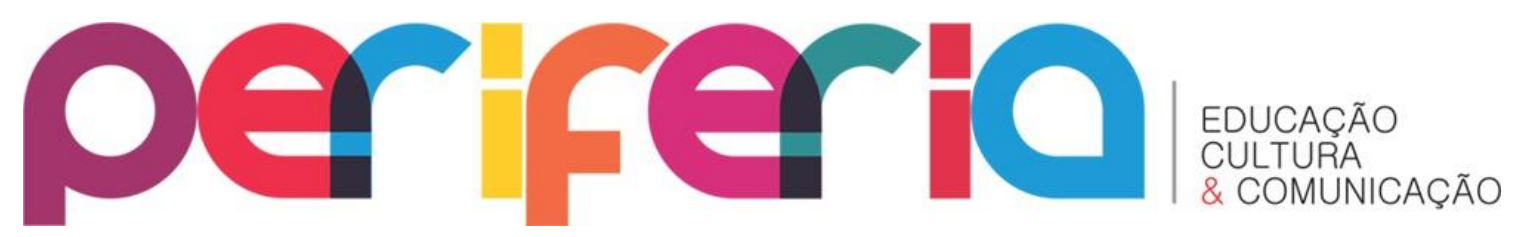

para encaminhamento do PROIN Mulheres para a comunidade Quilombola da Mutuca desse município. O Nedet visitou o Município de Jangada, especificamente a comunidade de Mutum que conta com a Associação de Mulheres: Feito por nós que conta com um trabalho importante de produção, mas que lamentavelmente tem a participação de poucas mulheres, hoje apenas algumas famílias participam desta associação.

\section{INTERLOCUÇÃO ENTRE UNIVERSIDADE E COMUNIDADES TRADICIONAIS, TERRITORIALIZANDO OS NÓS}

Nos últimos dois anos, procuramos constituir uma Rede de Pesquisa entre professores da UNEMAT e da UFMT, onde nossos/as acadêmicos/as tem tido a possibilidade de realizar seus mestrados e doutorados, além dos docentes realizar o pós-doutoramento. Mais do que rede de pesquisa, esta rede de trabalho e solidariedade, rede trançada por suor e lágrimas de professores que acreditam no bem viver, acreditam que o papel da universidade para além do tripé: Ensino, Extensão e Pesquisa, é o da crítica radical e é estar do lado dos pobres e oprimidos, tentar com eles encontrar saídas e soluções para as dificuldades que imperam por exemplo a produção, a circulação dos produtos e a comercialização dos seus produtos.

Acredita-se que a realização deste tipo de evento por professores ligados a diversos setores da universidade, que trabalham com populações marginalizadas e invisibilizadas democratiza o acesso à cultura e ao conhecimento, como a produção cultural e o fortalecimento das tradições locais e os laços de pertencimento da cultura negra ou indígena presente nesta porção do território matogrossense e que historicamente foram excluídas (invisibilizadas) da produção cultural e científica.

Pretendemos contribuir para a aproximação da universidade, com alunos da Educação Superior e com a Educação do Ensino Fundamental e Médio, fortalecendo a compreensão da oralidade, da leitura e a escrita, pois estes são processos que se conectam a diferentes áreas do conhecimento e a partir das leituras que a cultura e a ciência podem propiciar problematizar e propor ações 


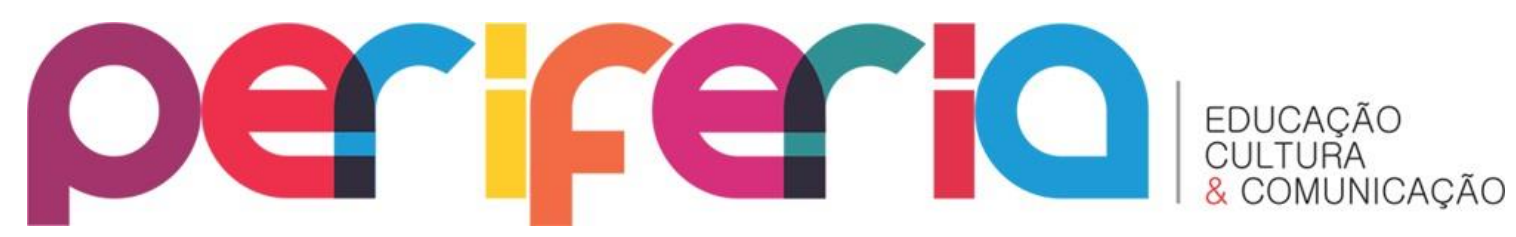

didáticas contextualizadas, originais e interculturais. Compreendemos que ao aproximar a Universidade da escola pública nos reconstituímos na esfera docente porque partilhamos experiências e aprendemos uns com os outros.

Espera-se sensibilizar para a integração das Mulheres dos Comitês de Mulheres dos Territórios Rurais e da Cidadania do Estado de Mato Grosso. A participação dos beneficiários se efetivará na forma de atendimento no que diz respeito à sensibilização dos prefeitos para a criação de Secretaria de Políticas para as Mulheres, e na efetividade do Comitê de Mulheres dos Territórios Rurais e da Cidadania do Estado de Mato Grosso (BRASIL, 2011).

Os Encontros de Mulheres que tem sido realizados tanto na UFMT/Cuiabá como em comunidades rurais, tem contado com espaços de documentários frutos de atividades pedagógicas midiáticas de vários projetos de pesquisa, ensino, extensão e cultura. Os documentários possibilitaram a evidência de histórias e saberes étnicos dos povos indígenas, participaram nesta atividade, três escolas indígenas da Terra Indígena Apiaká-Kayabi com trabalhos que foram realizados pelo Programa Novos Talentos/CAPES (Coordenação de Aperfeiçoamento de Nível Superior) e pelo Observatório de Educação Escolar Indígena, financiado pela FAPEMAT (Fundação de Amparo à Pesquisa). Além das atividades midiáticas haverá as produções escritas em forma de banner e exposição oral dos saberes a todos os visitantes do evento.

Além de ter a finalidade de expor para a comunidade acadêmica e à população, produções científico-culturais produzidas pelos Grupos de Pesquisas, COEDUC (Corpo Educação e Cultura/CNPq/UFMT) e LEAL (Laboratório de Estudos e Pesquisas da Diversidade da Amazônia Legal/CNPq/UFMT), em interação com estudantes da educação básica (anos finais do ensino fundamental e ensino médio).

Espera-se ainda valorizar e consolidar as experiências de institucionalização do debate das políticas públicas de Mulheres no âmbito dos Territórios da Cidadania e da Identidade, a partir da ação nos Comitês Territoriais de Mulheres e outros espaços de proposição de políticas públicas para as Mulheres. Esta ação está sob autonomia dos/as jovens rurais, designados a executar, avaliar ou acompanhar políticas públicas dessa natureza, além de Periferia, v. 10, n. 2, p. 103-118, jul./dez. 2018 


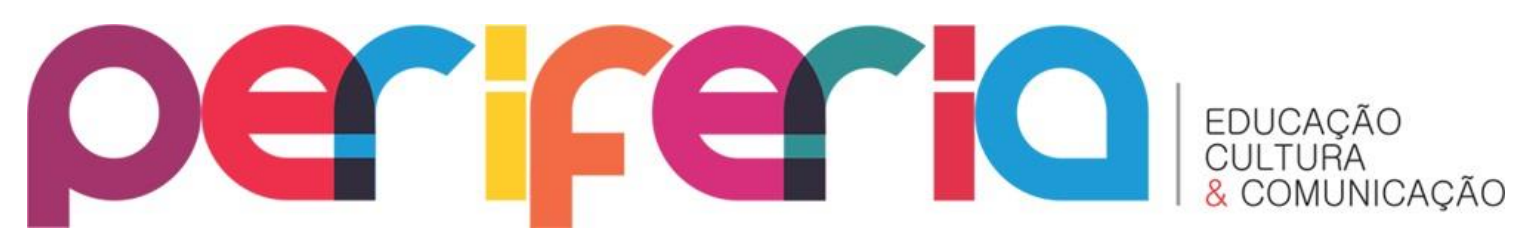

discutir as estratégias de fortalecimento das políticas para as mulheres e a democratização da participação das mulheres nas diversas esferas institucionais e federativas.

Assim, como nos processos de controle das políticas públicas e nas suas múltiplas formas de organização e de manifestação espera-se também reforçar a efetividade do debate sobre o enfrentamento das desigualdades entre mulheres e homens. O objetivo é o fortalecimento de sua capacidade interinstitucional com as instâncias governamentais estaduais e municipais e de intersetorialização das políticas públicas para mulheres.

As condições de vida das mulheres do campo têm sido incluídas nas agendas políticas brasileiras, mas o avanço nas políticas públicas para a igualdade de gênero do ponto de vista estrutural, ainda é lento e carece de investimentos nas várias esferas da sociedade, como na educação, trabalho e renda, acesso a saúde, espaços políticos de poder, etc.

0 enfoque nas práticas de economia solidária ora realizadas pelas mulheres que compõem o Território da Baixada Cuiabana, aparece como um elemento importante para a superação das desigualdades sociais e de gênero, a economia solidária tem se revelado como importante para a superação da economia capitalista e de fortalecimento de culturas locais.

O cuidado com o outro, é um assunto a ser debatido por nós mulheres líderes em educação, pois o trabalho feminino é por demais penoso fora de casa, para recair sobre ela apenas o cuidado com outro como meramente trabalho da mulher, além da superação dessa forma de percebê-lo carece de ser visto como ação política de todo ser humano.

Um dos instrumentos de participação popular têm sido as audiências públicas. O NEDET contribuiu para a articulação de produtoras e produtores dos 14 municípios da Baixada Cuiabana em diversas ações como na Audiência Pública sobre Agricultura Familiar realizada em Junho de 2015 na Central de Agricultura Familiar do Território da Cidadania na cidade de Várzea Grande.

Além do debate propiciado para a diminuição da distância entre políticas públicas e a realidade vivenciada pela população do campo, 


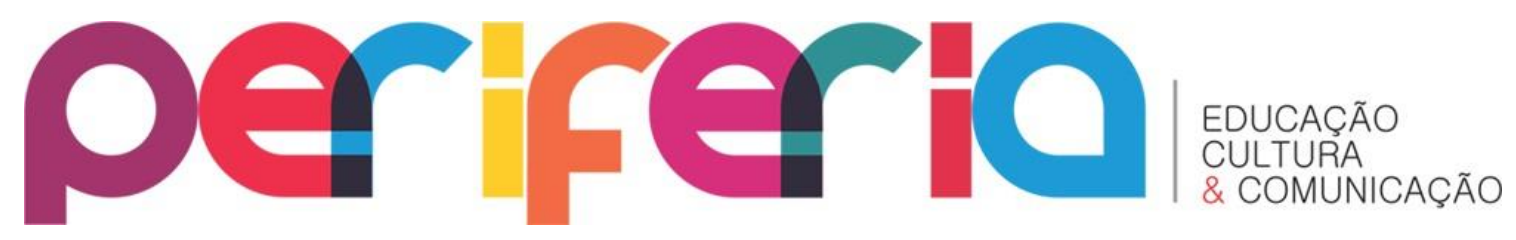

oportunizou-se a comercialização em feiras de alimentos produzidos agroecologicamente, bem como a produção de artesanato e doces.

Nesta audiência pública diversos agricultores e diversas agricultoras, trabalhadores e trabalhadoras do campo e da feira apresentaram suas demandas alegando o descaso política com a agricultura familiar na Baixada Cuiabana, pois é notório o descaso do poder público dos trabalhadores/as o que dificulta, a continuidade de uma produção num lugar em que o clima não favorece a produção. A ausência do poder público enfraquece a agricultura familiar que não dispõe de todos os meios de trabalho e precisa do apoio de maquinário, técnico e financeiro para potencializar a produção.

As mulheres agricultoras têm demonstrado o protagonismo, diante de tantos obstáculos reafirmando o sentimento de pertencimento a terra. As falas mostram a trama cultural estabelecida nesta sociedade e da qual todas nós fazemos parte, e ainda confirmam que imposição da condição de classe da população pela política e pelo sistema econômico que continuam a garantir privilégios para pequena parcela de homens, brancos e da elite.

Por outro lado, há processos de resistências sempre nas falas das agricultoras, que apontam que mesmo em comunidades tradicionais e de difícil acesso, há uma luta em curso e isto está relacionado ao pertencimento a que Freire (1989) chamou de assunção da identidade cultural. Para Passos (2010, p. 27) “a identidade, com a qual nos fazemos e que também nos faz, entre muitas coisas, é o grande elo de cada um de nós, como seres vivos, com as gerações que nos precederam e que virão após nós: este elo chama-se cultura”.

Como forma de compreender-se como ser social e culturalmente, há avanços significativos nas elaborações e implementação das políticas públicas para o desenvolvimento econômico e social das mulheres do campo. Isto pode ser visualizado no Plano Nacional de Políticas para as Mulheres (2013-2015).

A política Territorial implementada até então, não resolve isoladamente o problema da participação social, mas amplia as possibilidades desta e contribuí para o redirecionamento do investimento público no desenvolvimento econômico e social das populações camponesas, quilombolas e tradicionais. Há a necessidade de articulação entre vários Ministérios para a Periferia, v. 10, n. 2, p. 103-118, jul./dez. 2018 


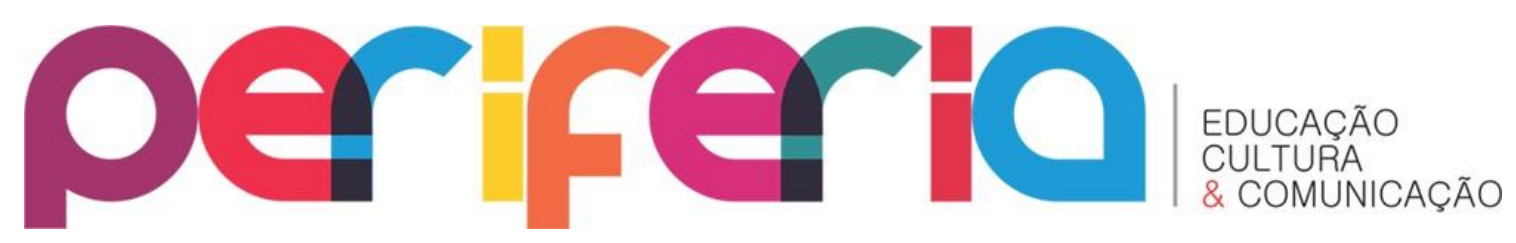

consolidação de uma política Territorial, sendo esta, a organização inicial do Programa.

A realização em outubro de 2016 do I Encontro Territorial de Mulheres do Estado de Mato Grosso, como evento paralelo ao SEMIEDU (Seminário de Educação da UFMT), promoveu círculos de saberes e trocas de experiências entre os sete territórios do Estado de Mato Grosso, sendo que dois desses territórios são da Cidadania e o restante Rural, além de contribuir com o fortalecimento, sobretudo do Comitê de Mulheres do Território da Cidadania da Baixada Cuiabana. 0 evento contribuiu para com a qualificação da participação dos/as jovens mulheres que vivem nos territórios rurais e da cidadania, ribeirinhos, quilombolas, indígenas, de povos e comunidades tradicionais, agricultores e agricultoras familiares, acampados e assentados da Reforma Agrária, em espaços de discussão sobre políticas públicas.

O trabalho com o Comitê de Mulheres tem sido possível através da articulação de uma rede de professores, trançadas por compromissos com uma sociedade melhor, e tem contribuído não só com os trabalhos de desenvolvimento territorial da Baixada Cuiabana, mas também com a melhoria da produção do conhecimento científico das escolas públicas do Vale do Arinos, com destaque aos municípios de Juara, Novo Horizonte do Norte e Porto dos Gaúchos, pois o grupo de pesquisa Leal é vinculada a UNEMAT/ Campus de Juara. Tanto o trabalho de criação, bem como o de formação do Comitê de Mulheres leva em conta o empoderamento das mesmas, para que atuem no meio em que vivem da forma mais independente possível, sobretudo que façam o enfrentamento contra a violência de gênero, muito presente, sobretudo no campo.

As ações empreendidas no interior do projeto é também uma forma de contribuir com o conhecimento acerca do patriarcado para que as mulheres dos territórios possam reivindicar e lutar por um lugar de igualdade junto ao lar, para que assumam o espaço de decisão no lote rural e que ajudem a decidir no que investir com o dinheiro da produção. 


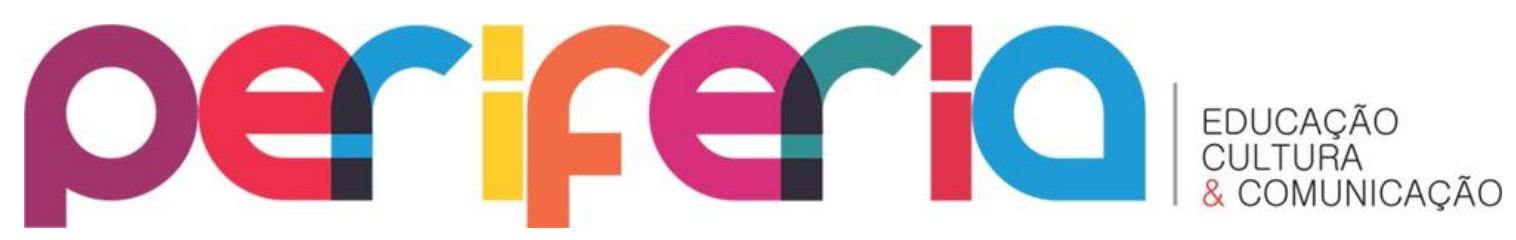

\section{CONSIDERAÇÕES FINAIS}

Infelizmente após dois anos de trabalho do Nedet Baixada Cuiabana junto ao Colegiado foi possível perceber que o Colegiado não caminha sozinho, como foi a proposição e/ou como deveria ser a partir da sua própria autonomia. Talvez isso ocorra porque os Territórios estão ligados a uma diversidade de pessoas com interesses políticos diversos. Nunca será demais a universidade discutir a partir da vivência e do chão do território conceitos como Participação e Democracia.

É desafiador qualquer iniciativa de se fazer um trabalho diferenciado e ligado ao social, sempre terá dificuldades a serem enfrentadas, mas é importante valorizar a representação das comunidades e o fortalecimento que está acontecendo neste percurso. O Nedet, em conjunto com o Colegiado, busca avançar com os Projetos e os parceiros que valorizam as ações territoriais a exemplo de alguns sindicatos e instituições governamentais.

Nesse emaranhado social, identificamos com muita evidência a participação das mulheres que assumem de maneira forte os rumos das organizações de suas comunidades, ações desenvolvidas não apenas por elas, mas em complementaridade com o sexo masculino, que participa, mas que aos poucos e com muita dificuldade tem aprendido a escutar a força feminina.

\section{REFERÊNCIAS}

BRASIL. Presidência da República. Secretaria Nacional de Enfrentamento à Violência contra as Mulheres. Secretaria de Políticas para as Mulheres. Mulheres do campo e da floresta: Diretrizes e ações nacionais. Brasília, 2011.

FREIRE. Paulo. A importância do ato de ler: em três artigos que se complementam. 23. ed. São Paulo: Autores associados, Cortez, 1989.

PASSOS, Luiz Augusto. Cultura: Flecha humana e cósmica que aponta o caminho para os sentidos. In: GRANDO, Beleni Salete. PASSOS, Luiz Augusto (Orgs). $O$ eu e o outro na escola: contribuições para incluir a história e a cultura dos povos indígenas na escola Cuiabá: EdUFMT, 2010. 


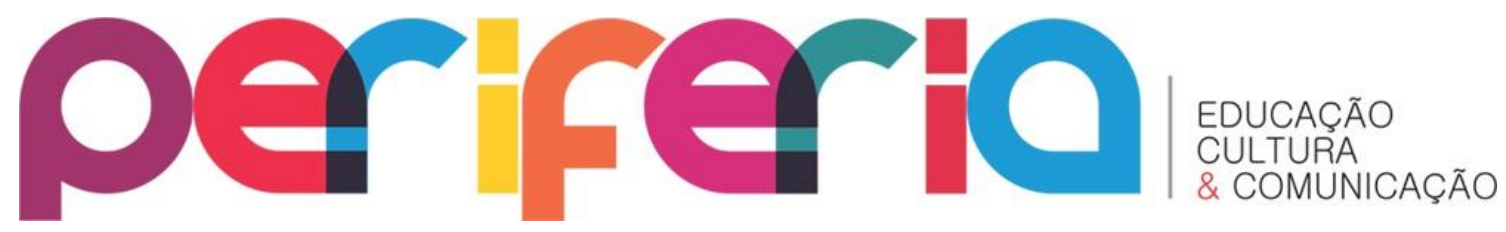

SANTOS, Boaventura de Souza. Introdução: do pós moderno ao pós-colonial e para além de um e outro". In A Gramática do Tempo. Porto: Afrontamento. (2006).

SANTOS, Boaventura de Souza. Epistemologias do Sul: Boaventura de Souza Santos em diálogo com Alice. Centro de Estudos Sociais da Universidade de Coimbra. Portugal, 22 a 30 de jun. 2016 a.

SANTOS, Boaventura de Souza. Para além do pensamento abissal: das linhas globais a uma ecologia de saberes In SANTOS, Boaventura de Souza \& MENEZES, Maria Paula (Orgs.). Epistemologias do Sul. São Paulo: Cortez, 2016 b. 